\title{
鋼はり一柱部材の耐荷力に関する統計的評価 \\ STATISTICAL EVALUATIONS OF STEEL BEAM-COLUMNS STRENGTH
}

\author{
塩 見 弘 幸*・事口寿 男水 \\ By Hiroyuki SHIOMI and Hisao KOTOGUCHI
}

\section{1. まえがき}

本報告は，はりー柱部材の 強度に関する 既往の実験值 を用い, 統計的見地から 国内外の 2,3 の規定の 強度相 関式について検討を行い，そのパラメーターを考察する ことにより，信頼性設計のための資料を得ることを目的 とするものである.なお，ここに利用した実験データは 文献 さ) で利用したものに，その後集録し得たデー夕を 加えたものである.

ここで扱うはりー柱は等断面に関するものとし，次の 3 つの場合について 考える. (1) 軸方向力と強軸まわり の曲げが 作用する場合の 面内耐荷力, (2) 軸方向力と強 軸まわりの曲げが作用する場合の 面外耐荷力, (3) 軸方 向力と 2 軸曲げが作用する場合の耐荷力. なお，(1) およ び (2)の場合を 1 軸曲げ，(3) の場合を 2 軸曲げと略記す る. 部材間に横荷重が作用する場合は対象外とし，断面 形状は $\mathrm{H}$ 形および I 形を対象とする.

\section{2. 基準耐荷力式について}

はり一柱の 基準耐荷力式としては，設計を容易にする ために簡略化した近似相関式が用いられている.この近 似相関式には種々のものがあるが，日本の道路橋示方 書 ${ }^{3)}$ (道示と略記）に規定されている次式のタイプが強 度相関式として比較的広く用いられている。

$$
\begin{aligned}
& \frac{P}{P_{u}}+\frac{M_{x 0} \cdot C_{E x}}{M_{u x}}\left(\frac{1}{1-P / P_{E x}}\right) \\
& +\frac{M_{y 0} \cdot C_{E y}}{M_{u y}}\left(\frac{1}{1-P / P_{E y}}\right)=1
\end{aligned}
$$

ここに, $P, M_{x_{0}}, M_{y_{0}}$ : それぞれ はり一柱の 軸方向荷 重と断面の強軸および弱軸まわりの材端作用モーメント

* 正会員 中部工業大学講師 土木工学科

** 证会員 工博 大同工業大学助教授 建設工学科
$P_{u}$ : 軸方向力のみが作用する場合の圧縮耐荷力, $M_{u x}$, $M_{u y}$ : 曲げモーメントのみが作用する場合の曲げ耐 荷力, $P_{E x}, P_{E y}:$ それぞれ曲げモーメント $M_{x 0}, M_{y_{0}}$ が作用する面内の Euler 荷重, $C_{E x}, C_{E y}$ : それぞれ曲 げモーメント $M_{x 0}, M_{y_{0}}$ が作用する面内での曲げモー メントの逓減係数である.これは, 部材の両端にそれぞ れ大きさの異なる曲げモーメントが作用する場合, 部材 中央の曲げモーメントの大きさを評価するために用いら れ， $M_{x e q}=M_{x 0} \cdot C_{E x}$ として換算される. $M_{x e q}$ はさら に増幅係数 $1 /\left(1-P / P_{E x}\right)$ によって増幅される.

\section{(1) 1 軸曲げ}

基準耐荷力式として道示, $\mathrm{AASHTO}^{4)}, \mathrm{AISC}^{5}$ ! 老用 いる. これらの 基準耐荷力式はそれぞれ式（1）の左辺 第 3 項を除いた形で表わされる. 各基準においては, 式 (1) の $P_{u}$ および $M_{u x}$ として 表一1 の基準式を用い ている.また, AASHTO, AISC では部材端で塑性ヒ ンジが形成される場合を考え, 式 (1) の左辺第 3 項を 除いた左辺の值と次式の左辺の值とを比べ，小さい方の 強度值を設計に用いている.

$$
P / P_{u}+M_{x 0} / M_{p x}=1
$$

ただし, $P_{u}=0.85 P_{y}$ (AASHTO), $P_{u}=P_{y}$ (AISC), $M_{p x}$ : 全塑性モーメント, $P_{y}$ : 軸方向力のみが 作用す る場合の降伏荷重.

\section{(2) 2 軸曲げ}

ここでは，道示と次式の Chen の提案式6)用いる.

$$
\left(M_{x 0} / M_{u x}\right)^{\mu}+\left(M_{y 0} / M_{u y}\right)^{\mu}=1
$$

$こ こ に$

$$
\left.\begin{array}{rl}
M_{u x}= & M_{m}\left(1-P / P_{u}\right)\left(1-P / P_{E x}\right) \\
M_{u y}= & M_{p y}\left(1-P / P_{u}\right)\left(1-P / P_{E y}\right) \\
M_{m}= & {\left[1.07-\left(l / r_{y}\right) \sqrt{\sigma_{y}} / 3161\right] M_{p x}} \\
& \leq M_{p x}\left(\sigma_{y} \text { の単位は ksi }\right) \\
\mu=1.4+P / P_{y}
\end{array}\right\},
$$


表一1 各基準耐荷力式 ( 1 軸曲げ）における $\boldsymbol{P}_{u}$ および $\boldsymbol{M}_{u x}$ の基準式

\begin{tabular}{|c|c|c|c|c|c|}
\hline 基準耐荷力式 & 杜の項に関 & する基準式 & はりの項に関 & する基準式 & \\
\hline 道 & $\begin{aligned} \frac{P_{u}}{P_{y}} & =1 \\
& =1.109-0.545 \bar{\lambda} \\
& =1 /\left(0.773+\bar{\lambda}^{2}\right)\end{aligned}$ & $\left.\begin{array}{l}\bar{\lambda} \leq 0.2 \\
0.2<\bar{\lambda} \leq 1.0 \\
1.0<\bar{\lambda}\end{array}\right\} \cdots \cdots($ a $)$ & $\begin{aligned} \frac{M_{u x}}{M_{y}} & =1 \\
& =1-0.412(\bar{\alpha}-0.2) \\
& =1 / \bar{\alpha}^{2}\end{aligned}$ & $\begin{array}{l}\bar{\alpha} \leq 0.2 \\
0.2<\bar{\alpha} \leq \sqrt{2} \\
\sqrt{2}<\bar{\alpha}\end{array}$ & $\{\cdots \cdots(b)$ \\
\hline AASHTO & $\begin{aligned} \frac{P_{u}}{P_{y}} & =0.85\left(1-0.25 \bar{\lambda}^{2}\right) \\
& =0.85 / \bar{\lambda}^{2}\end{aligned}$ & $\begin{array}{l}\bar{\lambda} \leq \sqrt{2} \\
\bar{\lambda}>\sqrt{2}\end{array}$ & $\begin{aligned} \frac{M_{u x}}{M_{y}} & =1-0.25 \bar{\gamma}^{2} \\
& =1 / \bar{\gamma}^{2}\end{aligned}$ & $\begin{array}{l}\bar{\gamma} \leq \sqrt{2} \\
\bar{\gamma}>\sqrt{2}\end{array}$ & \\
\hline AISC & $\begin{aligned} \frac{P_{u}}{P_{y}} & =1-0.25 \bar{\lambda}^{2} \\
& =1 / \bar{\lambda}^{2}\end{aligned}$ & $\begin{array}{l}\bar{\lambda} \leq \sqrt{2} \\
\bar{\lambda}>\sqrt{2}\end{array}$ & $\begin{array}{c}\frac{M_{u x}}{M_{p x}}=1.07-\frac{l / r_{y} \sqrt{\sigma_{y}}}{3161} \leq 1 \\
\quad\left(\sigma_{y} \text { の単位 }: \mathrm{ksi}\right)\end{array}$ & \} & ) \\
\hline
\end{tabular}

\section{3. 既往の実験値について}

1 軸曲げに関する実験資料》にについて，面外耐荷力に 関する実験資料のらち，Vankuren-Galambos がまとめ た資料を AO-1 とする. この場合の載荷方法は, 中心 軸圧縮力を一定值に保ち曲げモーメントを増加させてい る. 部材端は一方向のみのナイフエッジによって支持さ れているため,強軸まわりの回転は完全に自由であるが， 弱軸まわりについては拘束された状態にある．弱軸に関 する部材の有効長は $0.6 l$ とする. Johnston-Cheney, Wisconsin 大学, Massonnet の実験をそれぞれ AO-2, AO-3, AO-4 とする.これらの場合の載荷方法はいずれ も偏心載荷で, AO-4 を除き, AO-1 と同様に部材端で は一方向のナイフェッジが用いられている. AO-4 の実 験では, 部材の両端は半球形状の台上に設置されている ため, 両軸まわりとも回転支持と考えられる. 面内耐荷 力実験に関する資料は，AO-1 と同シリーズ中の 10 体 のみで，これを AI-1 とする． 2 軸曲げに関する実験資 料に関しては, Klöppel-Winkelman ${ }^{8)}$, Birnstiel ${ }^{9)}$, およ び Massonnet ${ }^{10)}$ の実験データをそれぞれ B-1，B-2 お よび B-3 とする.

\section{4. 基準耐荷力值に対する実験值の統計処理}

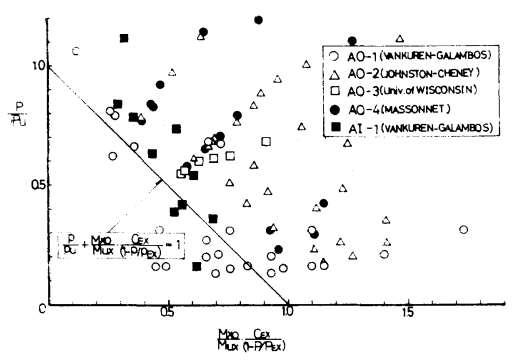

図一1 道路橋示方書の基準耐荷力式によるパラ メーターで整理した実験值 (1 軸曲げ)

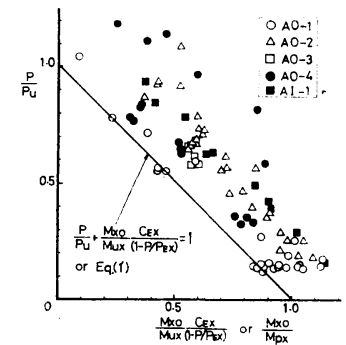

図一2 AASHTO の基準耐荷力式 によるパラメーターで整理 した実験値 (1 軸曲げ)

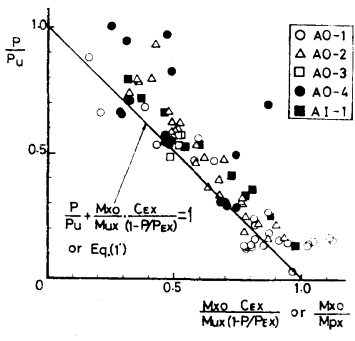

図一3 AISC の基準耐荷力式による パラメーターで整理した実験 值 ( 1 軸曲げ) 


\section{表一2＼cjkstart各基準耐荷力式による計算結果}

(a) 1 軸曲 げ

\begin{tabular}{|c|c|c|c|c|c|}
\hline \multirow{2}{*}{ 対 象 } & \multirow{2}{*}{$\begin{array}{l}\text { 基 準 } \\
\text { 耐荷力式 }\end{array}$} & \multirow{2}{*}{ 資料数 } & $P_{m}$ & $S_{d}$ & $V_{p}$ \\
\hline & & & $P_{m}^{\prime}$ & $S_{d^{\prime}}$ & $V_{p^{\prime}}$ \\
\hline \multirow{6}{*}{ 随外 } & \multirow{2}{*}{ AASHTO } & \multirow{2}{*}{77} & 1.162 & 0.093 & 0.080 \\
\hline & & & 1.206 & 0.127 & 0.105 \\
\hline & \multirow{2}{*}{ AISC } & \multirow{2}{*}{77} & 1.109 & 0.106 & 0.096 \\
\hline & & & 1.149 & 0.120 & 0.104 \\
\hline & \multirow{2}{*}{ 道 } & \multirow{2}{*}{77} & 1.279 & 0.299 & 0.234 \\
\hline & & & 1.376 & 0.397 & 0.289 \\
\hline \multirow{2}{*}{ 面内 } & \multirow{2}{*}{ 道 } & \multirow{2}{*}{10} & 1.107 & 0.111 & 0.164 \\
\hline & & & 1.137 & 0.122 & 0.169 \\
\hline
\end{tabular}

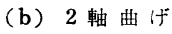

\begin{tabular}{|c|c|c|c|c|}
\hline \multirow{2}{*}{$\begin{array}{l}\text { 基 準 } \\
\text { 㴬鿉力式 }\end{array}$} & \multirow{2}{*}{ 資料数 } & $P_{m}$ & $S_{d}$ & $V_{p}$ \\
\hline & & $P_{m}^{\prime}$ & $S_{d^{\prime}}$ & $V_{p^{\prime}}$ \\
\hline 道 示 & 162 & $\begin{array}{l}1.429 \\
1.390\end{array}$ & $\begin{array}{l}0.189 \\
0.196\end{array}$ & $\begin{array}{l}0.132 \\
0.141\end{array}$ \\
\hline CHEN-1 & 162 & $\begin{array}{l}0.856 \\
0.867\end{array}$ & $\begin{array}{l}0.127 \\
0.128\end{array}$ & $\begin{array}{l}0.149 \\
0.148\end{array}$ \\
\hline CHEN-2 & 162 & $\begin{array}{l}1.013 \\
1.035\end{array}$ & $\begin{array}{l}0.134 \\
0.139\end{array}$ & $\begin{array}{l}0.132 \\
0.134\end{array}$ \\
\hline
\end{tabular}

の C 曲線に 近似させた式を用い，さらに，式 $(2)^{\prime}$ の $M_{m}$ を $M_{m}=M_{p x}$ とした場合である.ほほ実験值の平 均を評価している.

\section{5. 強度相関式に関する考察}

前節では入手し得た国内外の実験データを用いて,二, 三の基準耐荷力式を検討した．その結果，道示の基準耐 荷力式に対しては，表一2，図一1 から明らかなよらに， ほかに比べ実験值のばらつきが相当大きい，その原因と しては次のようなことが考えられる.

(1) 道示のはりの基準耐荷力式では, 弾性横倒れ座屈 応力式のうち, St. Venant のねじりによる応力の項を無 視し，横倒れ座屈パラメーター $\bar{\alpha}$ が定められている ${ }^{11)}$. しかし，実験に供されたはり一柱部材のウェブ高さは一 般に低く, St. Venant のねじりの影響が大きい. (2) 道 示の柱の基準耐荷力式では, ECCS の multiple column curves のうち，下限值近くの曲線に類似した式が用い られている。 これは溶接 $\mathrm{H}$ 形鋼柱の耐荷力曲線に近い が，実験に供された部材はいずれも圧延 $\mathrm{H}$ 形鋼であり， これらの柱の 耐荷力曲線は，溶接 $\mathrm{H}$ 形鋼柱の 耐荷力曲 線よりも上側に位置している. (3) 道示では, 部材端で 塑性ヒンジが発生する場合を評価する相関式が規定され ていない，既往の実験データには，明らかに部材端で塑 性ヒンジが発生し崩壊に至ったとみられるものもある。 図一1 において，直線式より内側の数点の実験值にその 傾向がみられる.

以上の諸点を検討することによって, 入手し得た実験
データの範囲におけるはり-柱部材に限定し，実験值の ばらつきがなるべく小さくなるような，はり一柱の強度 相関式を考えてみる. ある程度小さな変動係数を示寸強 度相関式を得ることができれば，たとえば文献 2)（に述 べられているような下界係数を用いることにより，信頼 度の高い下界值を示すことが可能となる．まず，はりに 関する基準值については, 弾性横倒れ座屈応力式から, そりねじりによる応力項を無視し，これを道示の座屈パ ラメーター $\bar{\alpha}$ を用いて表わす. 両端単純支持の場合の はりの弾性横倒れ座屈応力式は ${ }^{11)}$,

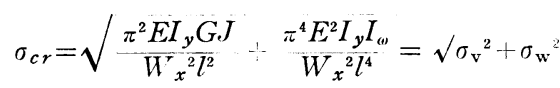

ここに, $E I_{y}: y$ 軸まわりの曲げ剛度, $G J$ : 断面のねじ り剛度, $E I_{\omega}$ : 断面のそりねじり剛度, $l:$ はりの長さで ある. $G=E / 2(1+\nu), \nu=0.3$ の関係を用いて, 式 (3) から

$$
\frac{\sigma_{\mathrm{v}}}{\sigma_{y}}=\frac{l}{\pi} \sqrt{2.6 I_{\omega}} \quad \frac{J}{\sigma_{y}}=\frac{\sigma_{\mathrm{w}}}{\pi} \sqrt{\frac{J}{2.6 I_{\omega}}} \frac{1}{\bar{\alpha}^{2}}
$$

式（4）を $1 / \beta^{\prime 2}$ とおくと

$$
\beta^{\prime}=\bar{\alpha} \sqrt{\pi / l \sqrt{2.6 I_{w} / J}}
$$

となる.ここで, このパラメーターを用いて, はりの曲 げ耐荷力実験值の表示を試みる. 図一4 は, 文献 12) に おける圧延はりと溶接はり（溶接はりは，桁高 $500 \mathrm{~mm}$ 以下のもの) の実験データについて綎軸に $M_{u} / M_{p}$, 横 軸に $\bar{\beta}\left(\bar{\beta}=\beta^{\prime} \sqrt{f}, f\right.$ は形状係数) を取り表わしたもの である. かなりばらつきがみられるが, 強度值は $\ddot{\beta} \leq 1$ でほぼ 1.0 を, $\bar{\beta}>1$ では $1 / \bar{\beta}^{2}$ に従う傾向を示して いる.したがって，はりに関する基準式は $\bar{\beta}$ を用いて 次のように考える.

$$
\left.\begin{array}{ll}
M_{u} / M_{p}=1.0 & \bar{\beta} \leq 1 \\
M_{u} / M_{p}=1 / \bar{\beta}^{2} & \bar{\beta}>1
\end{array}\right\}
$$

次に柱に関する 基準式について 検討する．はりー柱に 関するばらつきを小さくするためには柱の基準值をも5 少し大きくとった方がよいように思われるので, 柱の実 験值の平均值近くを表わしている AISC の柱の基準式 （表一1，式（e)）を用いることにする.

最後に (3)について考える. いま $\bar{\beta}<1, C_{E x} /(1-P /$ $\left.P_{E x}\right)<1$ の場合を考えてみると, 部材端の曲げモーメ ント $M_{x 0}$ が増幅された部材中央の曲げモーメントより も大きいため, 部材端で塑性ヒンジが生じる可能性があ る. したがって, この場合の強度相関式としては, AA SHTO, AISC で定めているように, 式 (1)'を用いる.

以上の 3 点を考慮した強度相関式を用いて実験値の統 計処理を行ったものが 表一3である.また，図一5 と 図一6 は考慮した変数を用いて, 実験値を図示したもの 


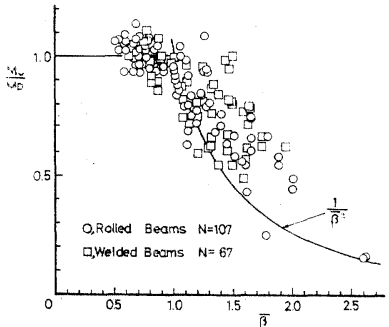

図一-4 $\bar{\beta}$ で整理したはりの曲げ耐荷 力実験值

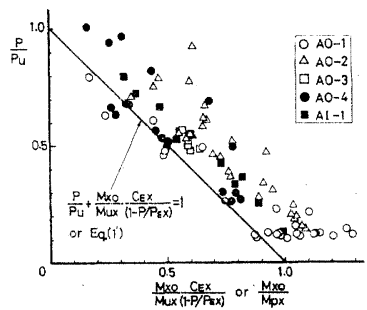

図一5 考察結果のパラメーターで整理 した実験值 ( 1 軸曲げ)
表一3 考察結果のパラメーターを用いた計算結果

\begin{tabular}{|c|c|c|c|c|c|c|}
\hline \multirow{2}{*}{ 対 } & \multirow{2}{*}{\multicolumn{2}{|c|}{ 象 }} & \multirow{2}{*}{ 資料数 } & $P_{m}$ & $S_{d}$ & $V_{p}$ \\
\hline & & & & $P_{m^{\prime}}$ & $S_{d^{\prime}}$ & $V_{p^{\prime}}$ \\
\hline \multirow{4}{*}{1 䡛曲以” } & & 外 & 77 & 1.034 & 0.080 & 0.077 \\
\hline & & & & 1.080 & 0.104 & 0.096 \\
\hline & & & 10 & 1.103 & 0.046 & 0.042 \\
\hline & & & 0 & 1.116 & 0.037 & 0.033 \\
\hline \multirow{2}{*}{2} & \multirow{2}{*}{ 曲 } & \multirow{2}{*}{$け ゙$} & \multirow{2}{*}{162} & 1.042 & 0.130 & 0.125 \\
\hline & & & & 1.055 & 0.125 & 0.119 \\
\hline
\end{tabular}

である.なお, 1 軸面内耐荷力の場合は, $M_{u x}=M_{p x}$ と おき面外耐荷力の図中に示した. 2 軸曲げに関する 図一 6 については, 式 (1) の左辺の合計值をべクトルとし, $x, y$ 軸に関する作用曲げモーメントの大きさによる方 向性を考慮して，原点から放射状にこれを取り示した。 図一5 から，1軸曲げの場合は，かなりばらつきが小さ くなっていることがわかる. なお, 強度相関式よりも安 全側に，大きく離れた数個の実験值の存在が 目につく が，これらの供試体諸元をみると, 細長比が大きく( =1.5 2.0) 弾性挙動を示す部材であることから, 式 (1) では説明がつかず，弾性はり一柱の相関式を用いな ければならないと考えられる. 図一6の 2 軸曲げに関す るものは, 1 軸曲げに比べばらつきが大きいが, 表一2 （b）と表一3 とを比べると道示の強度相関式を用いた ものよりも変動係数は小さくなっている.したがって, この相関式は， 2,3 の強度相関式を用いて計算した值と 比較して変動係数も小さく, $P_{m}$ の值も 1 軸曲げ 2 軸曲 げともに同程度の值を示していることから, 対象とした はりー柱部材に対しほぼ一定の評価を下していると考え られる。

\section{6. あとがき}

はりー柱部材の実験資料の集録に努め,これらを国内 外の备基準耐荷力式のパラメーターについて整理した. その結果, 道示の強度相関式に対しては他の示方書のそ れらに比較して, ばらつきが大きいことが認められた。 そこで, 道示の強度相関式における柱およびはりの項に 関するそれぞれの基準式を検討し，実験值をよりよく評

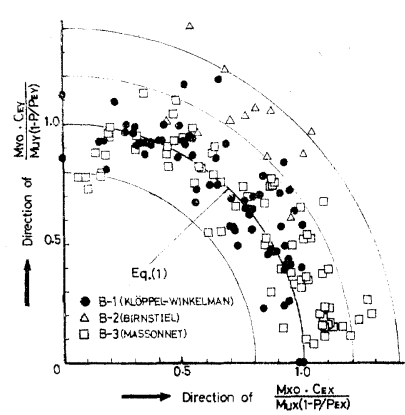

図一6 考察結果のパラメーターで整理した 実験值 ( 2 軸曲げ)

価する強度相関式を提示した。なお，既往の実験データ には含まれていないような，はり高の大きいはり一柱部 材に関しては, 今後実験データの集積を待ってからの検 討課題であると考えられる.

謝辞: この研究においては, 名古屋大学工学部, 福本唀士教授の指導を賜った. また，東海鋼構造研究グ ループ (代表 福本教授) の諸氏には，資料の提供と貴 重な助言を受けた。ここに記して謝意を表わす。

\section{参 考 文 献}

1）たとえば, Fukumoto, Y., Y. Itoh and M. Kubo: Strength variation of laterally unsupported beams, Proc. ASCE, Vol. 106, No. ST 1, pp. 165 181, 1980.

2) 福本唀士ほか：鋼構造部材の 抵抗強度の評価と信賴性設 計への適用, 橋梁と基礎, Vol. 14, Nos. 11 12, 1980.

3）日本道路協会：道路橋示方畫・同解説，昭和 55 年 2 月.

4) AASHTO : Standard Specification for Highway Bridges, 12 ed., 1977.

5) AISC Specification for the Design: Fabrication and Erection of Structural Steel for Buildings, Nov. 1, 1978 ed.

6) Tebedge, N. and W.F. Chen : Design criteria for $\mathrm{H}^{-}$ columns under biaxial loading, Proc. ASCE, Vol. 100, No. ST 3, pp. 579 598, 1974.

7）塩見弘幸・事口寿男 : はり一柱の抵抗強度の評㑛と信頼 性, 第 35 回土木学会年次学術講演会講演概要集 第 1 部, pp. 673 674, 昭和 55 年 9 月.

8) Klöppel, K. and E. Winkelmann : Experimentelle und theoretische Untersuchungen über die Traglast von zweiachsig außermittig gedrückten Stahlstäben, Der Stahlbau, Vol. 31, No. 4, pp. 109 119, 1962.

9) Birnstiel, C. : Experiments on H-Columns under Biaxial Bending, Proc. ASCE, Vol. 94, No. ST 10, pp. 2429 2449, 1968.

10) Anslijn, R. and C. Massonnet : New tests on steel I beam-columns in mild steel subjected to thrust and biaxial bending, Technishe Hochschule Darmstadt, Darmstadt, pp. 103 122, 1978.

11）福本唀士：プレートガーダーのフランジの曲げ圧縮強度, 橋梁と基礎, Vol. 6, No. 8, pp. 1 6, 1972.

12) Fukumoto, Y. and M. Kubo : An Experimental Review of Lateral Buckling of Beams and Girders, International Colloquium on Stability of Structures under Static and Dynamic Loads, ASCE, pp. 541 $562,1977$.

(1981.1.16 - 受付) 